\title{
Intoxicação por Baccharidastrum triplinervium (Asteraceae) em bovinos ${ }^{1}$
}

\author{
Ingeborg Maria Langohr²*, Aldo Gava ${ }^{3}$ e Claudio S.L. Barros ${ }^{4}$
}

\begin{abstract}
Langohr I.M., Gava A. \& Barros C.S.L. 2005. [Poisoning in cattle by Baccharidastrum triplinervium (Asteraceae).] Intoxicação por Baccharidastrum triplinervium (Asteraceae) em bovinos. Pesquisa Veterinária Brasileira 25(4):235-238. Animal Disease Diagnostic Laboratory, Purdue University, 406 South University, West Lafayette, IN 47907, Estados Unidos. E-mail: ilangohr@purdue.edu

An outbreak of poisoning by Baccharidastrum triplinervium in cattle from Paraná, Brazil, is described. The disease occurred during a severe drought in early summer. The onset of clinical signs was two days after 50 cows and 8 heifers had been introduced into a pasture with high density of $B$. triplinervium that showed signs of having been consumed by the animals. Fifteen animals ( 9 cows and 6 heifers) got sick. Of these 15 , two cows and four heifers died after a clinical course of 12-60 hours. Clinical signs included depression, ruminal atony, moderate bloat, marked dehydration, mild diarrhea and anorexia. The animals were restless, laying down and getting up constantly, remaining progressively longer periods in sternal recumbency. Once in that position, the animals had an extended head or the head turned to one of the sides of the body, and were groaning. Additionally, the cows had an abrupt fall in milk yield. The remaining affected cattle presented milder clinical signs and were partially back to their feed on the day following the onset of the clinical signs. The milk production was back to normal values within one week. The main gross lesions observed in two necropsied cows were in the forestomachs and abomasum, consisting of edema of the ruminal wall, as well as of diffuse reddening of the mucosae of the rumen, reticulum, abomasum and of some of the omasal folds. The main histological lesions included multifocal ballooning degeneration and necrosis of the lining epithelium of the rumen, associated with neutrophilic infiltrate. The diagnosis was based on the epidemiological data and on the experimental reproduction of the disease by force-feeding 3 bovine with the aeral fresh parts $(20$ and $30 \mathrm{~g} / \mathrm{kg})$ of B. triplinervium. Chemical analysis of dried material from B. triplinervium harvested at the site of the outbreak was negative for macrocyclic trichothecenes.
\end{abstract}

INDEX TERMS: Poisonous plants, Baccharidastrum triplinervium, Asteraceae, plant poisoning, diseases of cattle, pathology.

RESUMO-- É descrito um surto de intoxicação por Baccharidastrum triplinervium em bovinos do Paraná, Brasil. A doença ocorreu no início do verão, durante um período de forte estiagem. Os sinais clínicos iniciaram dois dias após a introdução de 50 vacas e 8 novilhas em uma pastagem com alta densidade de B. triplinervium, que apresentava sinais de ter sido consumido pelos animais.

\footnotetext{
${ }^{1}$ Recebido em 2 de setembro de 2005.

Aceito para publicação em 26 de outubro de 2005.

2 Animal Disease Diagnostic Laboratory, Purdue University, 406 South University, West Lafayette, IN 47907, Estados Unidos. *Author for correspondence. E-mail: ilangohr@purdue.edu

${ }^{3}$ Centro de Ciências Agroveterinárias, Universidade do Estado de Santa Catarina (UDESC), Av. Luiz de Camões 2090, Lages, SC 88520-000.

${ }^{4}$ Departamento de Patologia, Universidade Federal de Santa Maria (UFSM), Santa Maria, RS 97105-900. Bolsista do CNPq.
}

Adoeceram 15 bovinos ( 9 vacas e 6 novilhas). Desses, morreram duas vacas e quatro novilhas após um curso clínico de 12 a 60 horas. O quadro clínico incluía prostração, atonia ruminal, timpanismo moderado, desidratação acentuada, diarréia e anorexia. Os animais ficavam inquietos, se deitavam e se levantavam constantemente, permanecendo cada vez mais tempo deitados em decúbito esternal. Uma vez nessa posição, manifestavam gemidos e mantinham a cabeça estendida ou voltada para o flanco. Adicionalmente, observou-se nas vacas queda abrupta da produção de leite. Os demais bovinos afetados apresentaram sinais clínicos mais leves, voltando a ingerir um pouco de alimento já no dia seguinte ao aparecimento dos sinais clínicos; a produção de leite voltou aos níveis normais uma semana após. As principais lesões macroscópicas, em dois animais necropsiados, foram observadas principalmente nos comparti- 
mentos gástricos. Consistiam de edema da parede do rúmen, e de avermelhamento difuso da mucosa do rúmen, do retículo, do abomaso e de algumas folhas do omaso. Histologicamente, as lesões mais importantes incluíam degeneração balonosa e necrose multifocal com infiltrado neutrofilico discreto no epitélio de revestimento do rúmen. $\mathrm{O}$ diagnóstico foi baseado em dados epidemiológicos e na reprodução experimental com as partes aéreas superiores (20 e $30 \mathrm{~g} / \mathrm{kg}$ ) de B. triplinervium em três bovinos. A análise química de material seco de B. triplinervium, colhido no local do surto, foi negativa para tricotecenos macrocíclicos.

TERMOS DE INDEXAÇÃO: Plantas tóxicas, Baccharidastrum triplinervium, Asteraceae, intoxicação por planta, doenças de bovinos, patologia.

\section{INTRODUÇÃO}

No início do verão de 1998-1999 ocorreram mortes em bovinos no município de Palmeira, Paraná. Evidências epidemiológicas e a reprodução experimental da doença indicam que a ingestão de uma planta, Baccharidastrum triplinervium ${ }^{5}$ (Fig.1 e 2), foi responsável por essas mortes. B. triplinervium não tinha, até então,

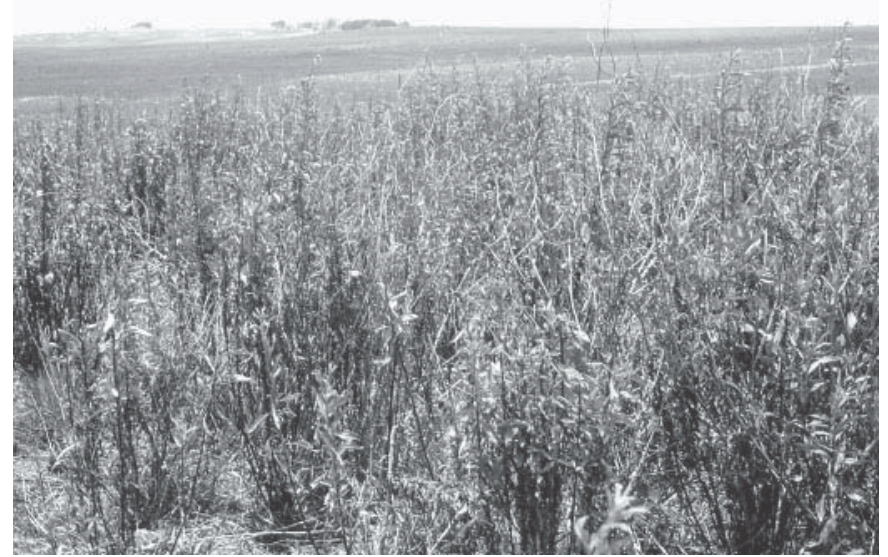

Fig.1. Campo nativo com alta densidade de Baccharidastrum triplinervium no local do surto, município de Palmeira, Paraná, no início do verão de 1998-1999.

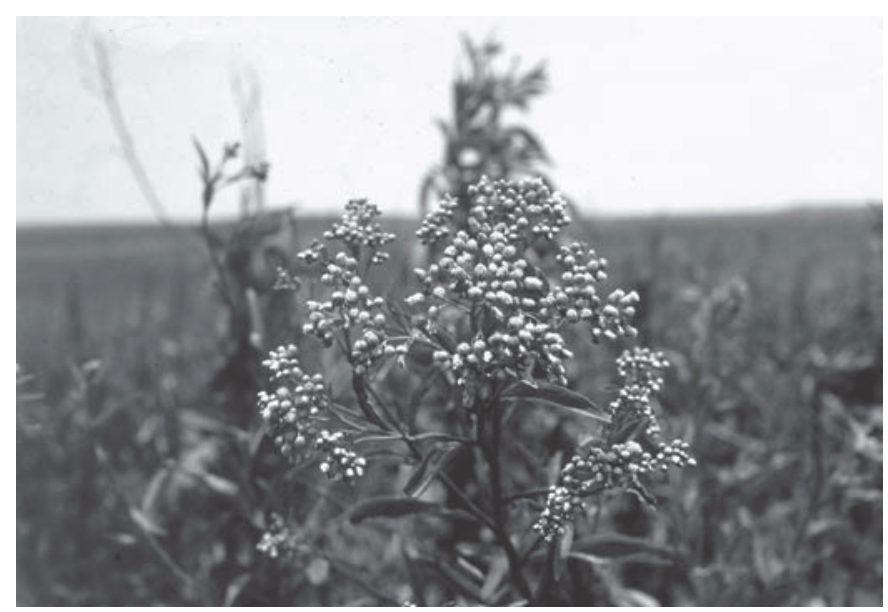

Fig.2. Baccharidastrum triplinervium com detalhes da inflorescência. Fotografia tirada em dezembro de 1998 no local do surto. sido associada a intoxicações em animais. Este trabalho descreve os dados epidemiológicos, sinais clínicos, achados de necropsia e histopatologia da intoxicação em bovinos por $B$. triplinervium e sua reprodução experimental.

\section{MATERIAL E MÉTODOS}

Os dados epidemiológicos e os sinais clínicos foram obtidos através de uma visita à propriedade onde ocorreu o surto. Dois animais foram necropsiados na propriedade. Como havia evidências que Baccharidastrum triplinervium tinha sido ingerida pelos animais que adoeceram, 20 e $30 \mathrm{~g} / \mathrm{kg}$ das partes aéreas superiores dessa planta (coletadas em dezembro de 1998 e 2001 no local do surto e em janeiro de 2002 em Lages, SC) foram administrados por via oral a quatro bovinos. Os dois bovinos experimentais que morreram também foram necropsiados. Fragmentos de várias vísceras de três bovinos necropsiados (uma vaca do surto espontâneo e dois bovinos da reprodução experimental) foram colhidos e processados rotineiramente para exame histológico e corados pela Hematoxilina e Eosina (HE). Devido a uma certa semelhança do quadro clínico e das lesões digestivas com a intoxicação por Baccharis coridifolia em bovinos, material da planta foi escrutinado por cromatografia em camada líquida em alta pressão para a presença de tricotecenos macrocíclicos. ${ }^{6}$

\section{RESULTADOS}

O surto ocorreu em um estabelecimento do município de Palmeira, localizado na região dos campos gerais, no estado do Paraná, no início do mês de dezembro de 1998, durante um período de forte estiagem. Cinqüenta e oito bovinos (50 vacas e 8 novilhas) foram colocados em uma pastagem envelhecida de azevém (Lolium multiflorum), trevo branco (Trifolium repens), trevo vermelho (Trifolium pratense) e serradela (Ornithopus sativus). Dessa pastagem, de aproximadamente 1,5 ha, os bovinos tinham acesso a um campo nativo normalmente úmido de cerca de 0,5 ha com alta densidade de Baccharidastrum triplinervium em floração. As partes aéreas superiores da planta apresentavam sinais de terem sido consumidas. Quinze bovinos (9 vacas e 6 novilhas) adoeceram dois dias após terem sido introduzidos na pastagem. A partir da retirada dos bovinos da pastagem infestada por B. triplinervium, não ocorreram novos casos. Após um curso clínico de 12-60 horas, morreram 2 vacas e 4 novilhas. Nove bovinos, afetados menos gravemente, se recuperaram uma semana após. $O$ proprietário informou que em anos anteriores os bovinos não tinham acesso ou tinham acesso reduzido a essa planta.

O quadro clínico dos animais afetados na intoxicação espontânea foi de evolução aguda ou subaguda e se caracterizou por

\footnotetext{
${ }^{5}$ Baccharidastrum triplinervium é um subarbusto da família Asteraceae, de 1,5-2,0m de altura, com folhas alternadas, trinervadas, ovadolanceoladas, de $5,5-11 \mathrm{~cm}$ de comprimento por $1,3-4 \mathrm{~cm}$ de largura. Os capítulos são muito numerosos, dispostos em densas cimas corimbiformes. As flores são dimorfas, sendo as marginais multisseriadas, numerosas, femininas, com corolas filiformes curtas, e as do disco somente em número de 2-6, masculinas. Essa espécie vegetal ocorre no sul do Brasil, Paraguai, Uruguai e nordeste da Argentina até o Delta e as margens do Rio da Plata (Burkart 1987).

${ }^{6}$ Realizado pelo Prof. Bruce B. Jarvis, do Department of Chemistry and Biochemistry, University of Maryland, College Park, MD, Estados Unidos.
} 
prostração, atonia ruminal, timpanismo moderado, desidratação acentuada, diarréia e anorexia. Os animais ficavam inquietos, se deitavam e se levantavam freqüentemente, permanecendo cada vez mais tempo deitados em decúbito esternal. Quando nessa posição, muitas vezes apresentavam a cabeça estendida ou voltada para o flanco e manifestavam gemidos. Adicionalmente, nas vacas, houve queda abrupta na produção de leite. Os demais animais afetados apresentaram sinais clínicos mais brandos e voltaram a ingerir um pouco de alimento já no dia seguinte, embora a diarréia tenha se mantido presente por vários dias; a produção de leite voltou aos níveis normais uma semana após o aparecimento dos sinais clínicos.

As alterações macroscópicas mais importantes foram observadas nos pré-estômagos e abomaso. Havia avermelhamento da mucosa do rúmen (principalmente nos sacos dorsal e ventral), do retículo, do abomaso, e de algumas folhas do omaso. Outros achados macroscópicos consistiam de fígado com coloração pálida, leve acentuação do padrão lobular e múltiplas áreas de hemorragia na superfície capsular. Havia sufusões na mucosa do íleo, sufusões subepicárdicas e subendocárdicas, e moderado edema pulmonar.

Ao exame microscópico, as lesões do rúmen correspondiam a degeneração balonosa e necrose multifocal com infiltrado neutrofílico discreto no epitélio de revestimento. Havia desprendimento do epitélio e edema transmural discreto, com dilatação moderada dos vasos linfáticos da mucosa e da submucosa. $\mathrm{O}$ figado apresentava moderada vacuolização hepatocelular difusa e necrose individual de hepatócitos. No baço não foram observadas alterações.

Dois bovinos experimentais, um que recebeu duas administrações com intervalo de 48 horas de $10 \mathrm{~g} / \mathrm{kg}$ e $20 \mathrm{~g} / \mathrm{kg}$ da planta coletada no local e na época do surto e outro que recebeu $20 \mathrm{~g} /$ $\mathrm{kg}$ da planta colegada coletada em janeiro de 2002 em Lages, SC, apresentaram anorexia, salivação, diarréia, atonia ruminal, decúbito prolongado, respiração abdominal ofegante e

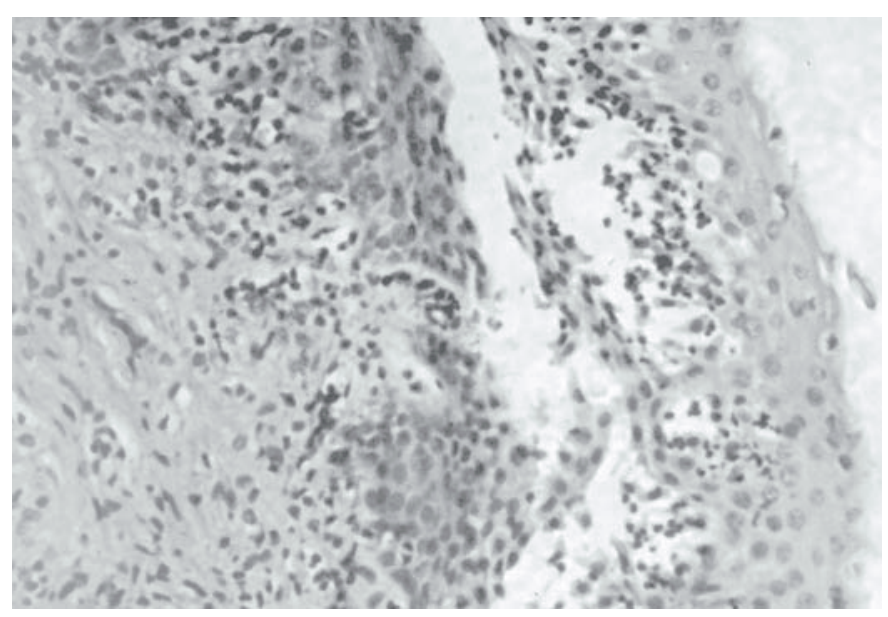

Fig.3. Necrose e desprendimento do epitélio do rúmen na intoxicação espontânea por Baccharidastrum triplinervium. A vesícula subepitelial formada pela separação do epitélio da submucosa contém discreto infiltrado de neutrófilos. Células inflamatórias também são observadas na submucosa. HE, obj.40. inquietude. Esses bovinos foram encontrados mortos 6 a 8 horas após o término da (segunda) administração da planta. 0 terceiro bovino adoeceu levemente 8 horas após ter recebido $20 \mathrm{~g} /$ $\mathrm{kg}$ da planta coletada no local do surto em dezembro de 2001. Os sinais clínicos se caracterizaram por leve anorexia, diminuição do número e da intensidade dos movimentos ruminais e fezes pastosas a líquidas. Esse animal se recuperou completamente dois dias após o início dos sinais clínicos. O quarto bovino, que também recebeu $20 \mathrm{~g} / \mathrm{kg}$ da planta coletada no local do surto em dezembro de 2001, não adoeceu.

Os achados de necropsia incluíam acentuado edema gelatinoso amarelado da parede ruminal na junção rumino-retículoomasal e avermelhamento moderado da mucosa ruminal. $O$ fígado tinha coloração pálida e havia sufusões no epicárdio e no endocárdio do coração esquerdo. As alterações microscópicas restringiam-se ao sistema digestivo, incluindo necrose do epitélio de revestimento (Fig.3), edema transmural acentuado, dilatação discreta dos vasos linfáticos da mucosa do rúmen, e necrose de coagulação de hepatócitos individuais. Os demais órgãos não apresentavam alterações macro ou microscópicas. A pesquisa de tricotecenos macrocíclicos resultou negativa.

\section{DISCUSSÃO}

O diagnóstico de intoxicação espontânea por Baccharidastrum triplinervium nesse estudo foi baseado em dados epidemiológicos e reprodução experimental dos quadros clínico, e anátomo e histopatológico. Evidências de que o surto espontâneo foi causado pela ingestão de $B$. triplinervium incluem a presença de grande quantidade dessa planta com sinais de ter sido consumida pelos bovinos e o aparecimento da doença coincidindo com a entrada dos bovinos nessa pastagem. Em anos anteriores, $\mathrm{o}$ acesso a essa planta era inexistente ou reduzido. Adicionalmente, os sinais clínicos e as lesões do surto espontâneo puderam ser reproduzidos em um novilho com a administração por via oral de B. triplinervium.

Os sinais clínicos e o quadro anátomo-patológico observados nos animais desse estudo são algo semelhantes aos encontrados em intoxicações por Baccharis coridifolia em bovinos (Tokarnia \& Döbereiner 1975, Barros 1993, Barros 1998, Varaschin et al. 1998, Rissi et al. 2005) e por B. megapotamica var. weirii e var. megapotamica em bovinos (Tokarnia et al. 1992). No entanto, o princípio ativo dessas plantas - tricotecenos macrocíclicos - não foi detectado em B. triplinervium. As condições que favorecem a intoxicação por plantas do gênero Baccharis são variáveis. Casos de intoxicação por B. coridifolia ocorrem somente em animais que desconhecem a planta, sendo observados principalmente em bovinos em trânsito e com fome após serem soltos em áreas com a planta (Tokarnia \& Döbereiner 1975). Presume-se que, em geral, B. triplinervium seja consumida em quantidades baixas, causando apenas distúrbios gastrintestinais leves sem resultar em morte dos animais. As condições que levaram os bovinos deste surto a ingerir grande quantidade de $B$. triplinervium parecem estar relacionadas ao acesso a uma área, em outros anos inacessível, com alta densidade da planta, bem como à escassez de forrageiras verdes devido a estiagem que acometia a região na época. A variação nos resultados obtidos na reprodução experimental do quadro clínico observado neste surto indica a provável coexistência de fatores ligados à 
planta (estado da planta - as plantas coletadas em 2001 eram pouco viçosas quando comparadas às coletadas em 1998 e 2002 -, solo e condições climáticas) e fatores ligados ao animal (resistência individual).

O quadro clínico-patológico observado neste surto também se assemelha de certa forma ao relatado na intoxicação experimental e espontânea por Plumbago scandens respectivamente em bovinos (Tokarnia \& Döbereiner 1982) e caprinos (Medeiros et al. 2001). O diagnóstico diferencial nesse caso pode ser feito baseado no local de ocorrência do surto e nos achados macroscópicos. P. scandens ocorre no Nordeste do Brasil e, portanto, em uma região no Brasil bem distante da em que ocorre $B$. triplinervium. Outro aspecto importante no diagnóstico da intoxicação pelas folhas de $P$. scandens é a coloração cinza-escura da mucosa do trato gastrintestinal superior e marrom-avermelhada da urina.

Os sinais clínicos e as lesões macro e microscópicas sugerem que a doença causada por $B$. triplinervium resulta da ação irritativa da planta na mucosa do trato gastrintestinal superior. No entanto, o princípio ativo da planta e a patogenia da intoxicação permanecem desconhecidos.

Agradecimentos.- Os autores agradecem ao Prof. Nelson Matzenbacher da Universidade Federal do Rio Grande do Sul, pela identificação da planta Baccharidastrum triplinervium e ao Prof. Bruce B. Jarvis do Department of Chemistry and Biochemistry da University of Maryland, College Park, MD, Estados Unidos, pelas análises químicas.

\section{REFERÊNCIAS}

Barros C.S.L. 1993. Intoxicação por Baccharis coridifolia, p.159-169. In: Riet-Correa F., Méndez M.C. \& Schild A.L. (ed.) Intoxicações por Plantas e Micotoxicoses em Animais Domésticos. Agropecuaria Hemisferio Sur S.R.L., Montevideo. 340p.

Barros C.S.L. 1998. Livestock poisoning by Baccharis coridifolia, p.569562. In: Garland T. \& Barr A.C. (ed.) Toxic Plants and Other Natural Toxicants. CAB International, Lallingford. 576p.

Burkart A. 1987. Flora ilustrada de Entre Ríos.Vol.6, p.247-249. INTA, Buenos Aires.

Medeiros R.M.T., Barbosa R.C., Lima E.F., Simões S.V.D. \& Riet-Correa F 2001. Intoxication by Plumbago scandens in goats in Paraíba, northeastern Brazil. Vet. Human Toxicol. 43:167-169.

Rissi D.R., Rech R.R., Fighera R., Cagnini D.Q., Kommers G.D. \& Barros C.S.L. 2005. Intoxicação espontânea por Baccharis coridifolia em bovinos. Pesq. Vet. Bras. 25:111-114.

Tokarnia C.H. \& Döbereiner J. 1975. Intoxicação experimental em bovinos por “mio-mio", Baccharis coridifolia. Pesq. Agropec. Bras., Sér. Vet. 10:7997.

Tokarnia C.H. \& Döbereiner J. 1982. Intoxicação experimental por Plumbago scandens (Plumbaginaceae) em bovinos. Pesq. Vet. Bras. 2:105-112.

Tokarnia C.H., Peixoto P.V., Gava A. \& Barros C.S.L. 1992. Intoxicação experimental por Baccharis megapotamica var. megapotamica e var. weirii (Compositae) em bovinos. Pesq. Vet. Bras. 12:19-31.

Varaschin M.S., Barros C.S.L. \& Jarvis B.B. 1998. Intoxicação experimental por Baccharis coridifolia (Compositae) em bovinos. Pesq. Vet. Bras. 18:6975 . 